\title{
Eugenol Induces Phenotypic Alterations and Increases the Oxidative Burst in Cryptococcus
}

\author{
Júnia C. O. Alves ${ }^{1}$, Gabriella F. Ferreira ${ }^{2 *}$, Julliana R. Santos ${ }^{3}$, Luís C. N. Silva ${ }^{3}$, \\ João F. S. Rodrigues ${ }^{3}$, Wallace R. N. Neto ${ }^{3}$, Emmanueli I. Farah ${ }^{3}$, Áquila R. C. Santos ${ }^{2}$, \\ Brenda S. Mendes ${ }^{1}$, Lourimar V. N. F. Sousa ${ }^{1}$, Andrea S. Monteiro ${ }^{3}$, Vera L. dos Santos ${ }^{4}$, \\ Daniel A. Santos ${ }^{4}$, Andrea C. Perez ${ }^{4}$, Thiago R. L. Romero ${ }^{4}$, Ângelo M. L. Denadaí ${ }^{2}$ and \\ Luciana S. Guzzo ${ }^{2}$ \\ 1 Faculdade de Ciências da Saúde, Universidade Vale do Rio Doce, Governador Valadares, Brazil, ${ }^{2}$ Departamento de \\ Farmácia, Universidade Federal de Juiz de Fora - Campus Governador Valadares, Governador Valadares, Brazil, ${ }^{3}$ Centro de \\ Ciências da Saúde, Universidade CEUMA, São Luís, Brazil, ${ }^{4}$ Instituto de Ciências Biológicas, Universidade Federal de Minas \\ Gerais, Belo Horizonte, Brazil
}

\section{OPEN ACCESS}

Edited by: Gordon Ramage, University of Glasgow,

United Kingdom

Reviewed by:

Fernanda Lopes Fonseca,

Centro de Desenvolvimento

Tecnológico em Sáude

(CDTS)/Fundação Oswaldo Cruz

(Fiocruz), Brazi

Ryan Kean,

University of the West of Scotland,

United Kingdom

*Correspondence:

Gabriella F. Ferreira

gabriella.freitas@uffif.edu.br

Specialty section:

This article was submitted to

Antimicrobials, Resistance

and Chemotherapy,

a section of the journal

Frontiers in Microbiology

Received: 08 August 2017 Accepted: 22 November 2017 Published: 07 December 2017

Citation:

Alves JCO, Ferreira GF, Santos JR,

Silva LCN, Rodrigues JFS, Neto WRN, Farah El, Santos ÁRC,

Mendes BS, Sousa LVNF,

Monteiro AS, dos Santos VL, Santos DA, Perez AC, Romero TRL,

Denadai ÂML and Guzzo LS (2017)

Eugenol Induces Phenotypic

Alterations and Increases

the Oxidative Burst in Cryptococcus.

Front. Microbiol. 8:2419.

doi: 10.3389/fmicb.2017.02419
Eugenol is a phenolic compound and the main constituent of the essential oil of clove India. Although there are reports of some pharmacological effects of eugenol, this study is the first that proposes to evaluate the antifungal effects of this phenol against both Cryptococcus gattii and C. neoformans cells. The effect of eugenol against yeast cells was analyzed for drug susceptibility, alterations in cell diameter, capsule properties, amounts of ergosterol, oxidative burst, and thermodynamics data. Data demonstrated that there is no interaction between eugenol and fluconazole and amphotericin B. Eugenol reduced the cell diameter and the capsule size, increased cell surface/volume, changed positively the cell surface charge of cryptococcal cells. We also verified increased levels of reactive oxygen species without activation of antioxidant enzymes, leading to increased lipid peroxidation, mitochondrial membrane depolarization and reduction of lysosomal integrity in cryptococcal cells. Additionally, the results showed that there is no significant molecular interaction between eugenol and C. neoformans. Morphological alterations, changes of cellular superficial charges and oxidative stress play an important role in antifungal activity of eugenol against C. gattii and C. neoformans that could be used as an auxiliary treatment to cutaneous cryptococcosis.

Keywords: eugenol, Cryptococcus gattii, Cryptococcus neoformans, antifungal activity, cutaneous cryptococcosis

\section{INTRODUCTION}

Cryptococcosis is a systemic mycosis caused mainly by Cryptococcus neoformans and C. gattii species (Hagen et al., 2015). Disseminated cryptococcosis is the worst prognostic of the disease, and can affect several organs beyond lungs, such as the central nervous system and skin (Chayakulkeeree and Perfect, 2006). Pathological manifestations in the skin, that occurs in 10$20 \%$ of patients, are characterized by different clinical features including ulcers, subcutaneous nodules, and cellulitis (Chayakulkeeree and Perfect, 2006; Capoor et al., 2008; Ikeda et al., 2014). The current antifungal therapies used for cryptococcosis such as amphotericin B and azoles have certain limitations due to side effects and emergence of resistant strains (Gast et al., 2013; 
Scorzoni et al., 2017). An alternative strategy for the treatment of cutaneous and subcutaneous cryptococcosis would be the application of formulations based on natural products derived from plants such as essential oils (Lemos et al., 2005; Baptista et al., 2015). In general, essential oils are complex mixtures of organic compounds, like diterpenes, monoterpenes, sesquiterpenes, and phenylpropanoids (Tadić, 2012; Gazim et al., 2014).

Phenylpropanoids are antimicrobial compounds characterized by a phenyl ring bearing a propenyl side chain (Louie et al., 2007). The eugenol [4-allyl-2-methoxyphenol] is the phenylpropanoid most widely studied for various biological activities (Louie et al., 2007; Carrasco et al., 2012; Perugini Biasi-Garbin et al., 2015). Previous research has shown that eugenol is a potent antifungal and antibacterial agent, and its antimicrobial action seems to be related to the inhibition of electron transport and perturbation of permeases in the cytoplasmic membrane (Gill and Holley, 2004; Darvishi et al., 2013). However, studies have shown that eugenol is related to the generation of oxidative stress concomitantly with lipid peroxidation of the cell membrane of Candida albicans yeast, and the generation of reactive oxygen species (ROS), that can also contribute to cell death (Khan et al., 2011).

Thus, based on the fact that eugenol is already well-described in literature as a potent antifungal and antibacterial agent, the aim of the present work was to investigate the antifungal effect of this phenol against both C. gattii and C. neoformans cells.

\section{MATERIALS AND METHODS}

\section{Cryptococcus Strains and Study Design}

For assays "Antifungal drug susceptibility testing" and "Timekill curves", we tested two reference strains of Cryptococcus gattii (ATCC 24065, ATCC 32608) and three reference strains of Cryptococcus neoformans (ATCC 24067, ATCC 28957, ATCC 62066) that were obtained from the Culture Collection of the University of Georgia (Atlanta, GA, United States). Six clinical isolates of C. gattii, five clinical isolates of C. neoformans, and one environmental isolate of each species, all from the Culture Collection of the Mycology Laboratory/ICB-UFMG, were also used in this study (Magalhães et al., 2013). Isolates were maintained on Sabouraud dextrose agar (SDA) at $4^{\circ} \mathrm{C}$. Prior to each test, the strains were subcultured on SDA for $48 \mathrm{~h}$ at $37^{\circ} \mathrm{C}$. Two reference strains of each species (C. gattii: ATCC 24065, ATCC 32068; C. neoformans: ATCC 28957, ATCC 62066) were chosen for further experiments.

\section{Antifungal Drug Susceptibility Testing}

The minimum inhibitory concentration (MIC) for eugenol (Sigma-Aldrich, St. Louis, MO, United States) was determined by the antifungal microdilution susceptibility standard test proposed by the CLSI M27-A3 method (Institute Clinical and Laboratory Standards, 2008). The inoculum was prepared in sterile saline and the transmittance of the suspensions was adjusted to $75-77 \%(530 \mathrm{~nm})$, followed by further dilution in
RPMI-1640 buffered with MOPS (Sigma-Aldrich, St Louis, MO, United States) medium to achieve $1.0 \times 10^{3}$ to $5.0 \times 10^{3}$ $\mathrm{CFU} / \mathrm{mL}$. The final concentrations ranged from 2 to $1024 \mathrm{mg} / \mathrm{L}$ for eugenol. The plates were incubated at $35^{\circ} \mathrm{C}$ for $72 \mathrm{~h}$. The MIC for eugenol was determined visually as $100 \%$ growth inhibition when compared to the control. The results were confirmed by adding the salt 3-(4,5-dimethylthiazol-2-yl)-2,5diphenyl-2H-tetrazolium bromide (MTT) (Sigma-Aldrich, St Louis, MO, United States) $(5.0 \mathrm{mg} / \mathrm{mL})$ to determine the reduction in the metabolic cell activity. Briefly, the plates were incubated at $35^{\circ} \mathrm{C}$ for $3 \mathrm{~h}$ and DMSO was added before spectrophotometric reading at $490 \mathrm{~nm}$. The MIC endpoint for interpreting the results was $100 \%$ of reduction in metabolic activity for eugenol compared with the control. The isolate Candida parapsilosis ATCC 22019 was used as a quality control. All the tests were performed in duplicate for each strain.

\section{Time-Kill Curves}

An assay was performed to evaluate the time-kill kinetics of the drugs against C. gattii and C. neoformans strains, as described previously (Ferreira et al., 2013). For eugenol, the concentration tested was equivalent to the MIC (256 mg/L - C. gattii: ATCC 24065, C. neoformans: ATCC 28957, ATCC 62066; $64 \mathrm{mg} / \mathrm{L} \mathrm{-}$ C. gattii ATCC 32068) or twice the MIC ( $2 \times$ MIC). Hundred microliter aliquot was taken from the microtitre plates containing the yeasts against the MIC and $2 \times$ MIC of eugenol at different intervals until $72 \mathrm{~h}$ and metabolic activity had been measured using MTT, as described above. The percentage of metabolic activity compared with control growth was determined for each strain for each time of reading. The results were confirmed by plating a quantity of each well on SDA and incubating at $37^{\circ} \mathrm{C}$ for $72 \mathrm{~h}$ for colonies counting.

\section{In Vitro Interaction of Eugenol with Fluconazole and Amphotericin B}

Eugenol was tested in combination with fluconazole and amphotericin B, the drugs usually chosen in cryptococcosis treatment. A checkerboard microdilution method, which provides a matrix of all possible drug combinations in the required concentration range, was used to test the susceptibility of the four Cryptococcus strains (two C. gattii and two C. neoformans) to the drugs. The eugenol concentrations and inoculum were prepared as described above. The concentrations of fluconazole and amphotericin B ranged from 0.125 to $64 \mathrm{mg} / \mathrm{L}$. A volume of $100 \mu \mathrm{L}$ of the inoculum suspension was transferred to sterile flat-bottom 96-well plates containing $50 \mu \mathrm{L}$ of each of the antifungal drugs and $50 \mu \mathrm{L}$ of eugenol or RPMI-1640 (control growth). The plates were incubated at $35^{\circ} \mathrm{C}$ for $72 \mathrm{~h}$. The cellular metabolic activity was determined using MTT salt. MIC endpoint analysis of the results was 50\% metabolic activity reduction for fluconazole and 100\% metabolic activity reduction for amphotericin B compared to the drug-free control.

The interaction between drugs was quantitatively evaluated by determining the fractional inhibitory concentration index (FICI) 
(Odds, 2003) . The formula for calculating FICI was: FICI $=[\mathrm{MIC}$ Fluconazole or Amphotericin B in combination with eugenol /MIC Fluconazole or Amphotericin B alone] + [MIC eugenol in combination with Fluconazole or Amphotericin B/MIC eugenol alone]. FICI was calculated for all the possible combinations of different concentrations. The interaction between these drugs was classified as synergism if FICI $\leq 0.5$, indifferent if $0.5>$ FICI $\leq 4.0$, and antagonism for FICI > 4.0. This assay was tested in duplicate and it was repeated twice.

\section{Sorbitol Test}

Sorbitol is used in a protection assay to provide clues if a drug interferes with the integrity of the cell wall, since it is an osmotic protector (Carrasco et al., 2012). A checkerboard microdilution method had been used to test the interference of sorbitol in the susceptibility of the four Cryptococcus strains (two C. gattii and two C. neoformans) to the eugenol. In this test, it was determined FICI eugenol with sorbitol as described above. The concentrations of sorbitol ranged from 0.05 to $0.8 \mathrm{~mol} / \mathrm{L}$ and of eugenol ranged from 16 to $1024 \mathrm{mg} / \mathrm{L}$. The reading was performed visually. All tests were performed in duplicates for each strain.

\section{Ergosterol Quantification}

C. gattii and C. neoformans strains were cultured on SDA $\left(37^{\circ} \mathrm{C}\right.$ for $72 \mathrm{~h}$ ) and treated with eugenol at MIC concentrations (MIC eugenol $=256 \mathrm{mg} / \mathrm{L}$ for C. gattii ATCC 24065, C. neoformans ATCC 28957 and C. neoformans ATCC 62066; 64 mg/L - C. gattii ATCC 32068) and fluconazole (positive control) for $1 \mathrm{~h}$ at $37^{\circ} \mathrm{C}$. A growth control was also performed. After incubation, the tubes were centrifuged (Jouan, model BR4i) at $1,643 \mathrm{~g}$ for $5 \mathrm{~min}$ at $4^{\circ} \mathrm{C}$ and the supernatant was removed. The cells were washed with sterile distilled water and the net wet weight pellet was determined, as described previously (Ferreira et al., 2013).

For the extraction of lipids, $3 \mathrm{~mL}$ of an ethanolic solution of potassium hydroxide $25 \%$ was added to each cell mass and agitated for $1 \mathrm{~min}$. The tubes were incubated in a water bath at $85^{\circ} \mathrm{C}$ for $1 \mathrm{~h}$ and further cooled at room temperature. A mixture of $1 \mathrm{~mL}$ of sterile water and $3 \mathrm{~mL}$ of $n$-heptane (Sigma-Aldrich, St Louis, MO, United States) was added, followed by agitation in a vortex for $3 \mathrm{~min}$. The supernatant was removed, and the reading was performed in a spectrophotometer at 282 and $230 \mathrm{~nm}$. A calibration curve with standard ergosterol (SigmaAldrich, St Louis, MO, United States) was constructed and used to calculate the quantity of ergosterol (Olsson et al., 1987; Santos et al., 2012). In all cases (ergosterol content from yeasts and standard ergosterol), the absorbance of ergosterol was the result from the subtraction of the absorbance obtained at $282 \mathrm{~nm}$ and absorbance obtained at $230 \mathrm{~nm}$. Ergosterol and 24(28) dehydroergosterol (DHE), a late sterol pathway intermediate, absorbed at $282 \mathrm{~nm}$, but at $232 \mathrm{~nm}$ the amount of absorption due to 24(28) DHE only (Breivik and Owades, 1957). The results were expressed as percentage of ergosterol in comparison with the growth control and represent the means of three independent experiments.

\section{Measurement of Mitochondrial Membrane Potential and Lysosomal Membrane Stability by Flow Cytometry}

Acridine orange (AO) (Olsson et al., 1987) and rhodamine 123 (Rho 123) (Ronot et al., 1986) were used as fluorescent probes for determination of lysosomal membrane stability and mitochondrial membrane potential $(\Delta \Psi \mathrm{m})$, respectively. For both assays, cells from each strain were resuspended at a density of $1 \times 10^{6}$ cells $/ \mathrm{ml}$ in $500 \mu \mathrm{L}$ in RPMI-1640 medium supplemented with MOPS. Eugenol was added at the concentrations of $1 \times$ MIC and $2 \times$ MIC, and the cells were incubated for $1 \mathrm{~h}$ (MIC) and $12 \mathrm{~h}$ (MIC and $2 \times \mathrm{MIC}$ ) at $37^{\circ} \mathrm{C}$ (MIC eugenol $=256 \mathrm{mg} / \mathrm{L}$ for C. gattii ATCC 24065, C. neoformans ATCC 28957, and C. neoformans ATCC 62066; $64 \mathrm{mg} / \mathrm{L}$ - C. gattii ATCC 32068). After incubation, the cells were washed three times with PBS buffer ( $\mathrm{pH}$ 7.2) under centrifugation at $6,000 \mathrm{rpm}$ for $10 \mathrm{~min}$. After washing, the cells pellets were resuspended in PBS $(500 \mu \mathrm{L})$ and labeled with AO $(1 \mu \mathrm{g} / \mathrm{mL}$ in the dark for $20 \mathrm{~min})$ or Rho $123(10 \mu \mathrm{g} / \mathrm{mL}$ in the dark for $10 \mathrm{~min}$ ). After incubation, cells were washed three times with PBS. The cells were resuspended in PBS and analyzed by flow cytometry (BD Accuri ${ }^{\mathrm{TM}}$, United States; FL3 channel for AO and FL1 for Rho123). A total of 10,000 events were analyzed for each sample. Changes in the fluorescent intensity of Rho 123 were quantified using the variation index (VI) obtained by the equation (MT-MC)/MC, where $\mathrm{MC}$ is the mean of fluorescent intensity of control and MT the mean of treated cells. Negative values of VI correspond to mitochondrial membrane depolarization.

\section{Fluorescent Microscopy}

Cells from each strain were resuspended at a density of $1 \times 10^{6}$ cells $/ \mathrm{mL}$ and treated with eugenol was added at the concentrations of $1 \times \mathrm{MIC}$ for $1 \mathrm{~h}$ at $37^{\circ} \mathrm{C}$. After incubation, the cells labeled with AO $(1 \mu \mathrm{g} / \mathrm{mL}$ in the dark for $20 \mathrm{~min})$ and recorded images $(40 \times$ ) by fluorescence microscopic system (Axio Imager Z2, Carl Zeiss, Germany) using 495-555 nm band pass (green) filter. Loss of lysosomal integrity can be observed as a rise in green fluorescence.

\section{Lipid Peroxidation Assay}

C. gattii and C. neoformans strains were cultured on $\mathrm{SDA}\left(37^{\circ} \mathrm{C}\right.$ for $72 \mathrm{~h}$ ) and treated with eugenol at MIC concentrations (MIC eugenol $=256 \mathrm{mg} / \mathrm{L}$ for C. gattii ATCC 24065, C. neoformans ATCC 28957 and C. neoformans ATCC 62066; $64 \mathrm{mg} / \mathrm{L}-$ C. gattii ATCC 32068) and hydrogen peroxide (positive control) for $1 \mathrm{~h}$ at $37^{\circ} \mathrm{C}$. The products of the lipid peroxidation were measured as thiobarbituric acid-reactive substances (TBARS) (Ferreira et al., 2013). The pellet was frozen and homogenized with $1 \mathrm{~mL}$ in ice cold $1.1 \%$ phosphoric acid. Four hundred microliter of the homogenate was mixed with $400 \mu \mathrm{L}$ of $1 \%$ thiobarbituric acid (Sigma-Aldrich, St Louis, MO, United States) prepared in $50 \mathrm{mM} \mathrm{NaOH}$ containing $0.1 \mathrm{mM}$ butylated hydroxytoluene and $200 \mu \mathrm{L}$ of $7 \%$ phosphoric acid (all the solutions were kept on ice during manipulation). Subsequently, samples ( $\mathrm{pH} 1.5$ ) were heated for $60 \mathrm{~min}$ at $98^{\circ} \mathrm{C}$ and $1500 \mu \mathrm{L}$ of butanol was 
added. The mixture was mixed vigorously using a vortex and centrifuged for $5 \mathrm{~min}$ at $2000 \mathrm{~g}$. The organic layer was transferred and the absorbance at $532 \mathrm{~nm}$ was measured (Termo Scientific Multiscan spectrum, Termo Ficher Scientific). The thiobarbituric acid solution was replaced by $3 \mathrm{mM} \mathrm{HCl}$ in the blank controls. TBARS values were calculated using the extinction coefficient of $156 \mathrm{mM}^{-1} \mathrm{~cm}^{-1}$ and represent the mean of three independent experiments.

\section{Measurement of ROS Production}

Endogenous ROS measured by fluorometric assay with specific probes (Ferreira et al., 2013). Yeast cells from C. gattii and C. neoformans cultured on SDA $\left(37^{\circ} \mathrm{C}\right.$ for $\left.72 \mathrm{~h}\right)$ were treated with $(\mathrm{MIC}$ eugenol $=256 \mathrm{mg} / \mathrm{L}$ for C. gattii ATCC 24065, C. neoformans ATCC 28957, and C. neoformans ATCC 62066; $64 \mathrm{mg} / \mathrm{L}$ - C. gattii ATCC 32068) and hydrogen peroxide (positive control) for $1 \mathrm{~h}$ in RPMI without phenol red (Sigma-Aldrich, St Louis, MO, United States) and incubated with $10 \mu \mathrm{M}$ of $2^{\prime}, 7^{\prime}$-dichlorofluorescin diacetate (DCFH-DA; Invitrogen, Life Technologies, Carlsbad, CA, United States) for ROS quantification. A growth control was also performed. The fluorescence was measured with a Fluorometer (Synergy 2 SL Luminescence Microplate Reader; Biotek) using excitation and emission wavelengths of $500 \mathrm{~nm}$. The results were expressed as arbitrary units of fluorescence \pm SEM. These tests were performed in triplicate.

\section{Antioxidant Enzymes Peroxidase and Superoxide Dismutase Activities}

Prior to the tests, a cell-free extract from yeast cells cultured on SDA $\left(37^{\circ} \mathrm{C}\right.$ for $\left.72 \mathrm{~h}\right)$ and treated with eugenol (MIC eugenol $=256 \mathrm{mg} / \mathrm{L}$ for C. gattii ATCC 24065, C. neoformans ATCC 28957, and C. neoformans ATCC 62066; $64 \mathrm{mg} / \mathrm{L}-$ C. gattii ATCC 32068) and hydrogen peroxide (positive control) was prepared and used for assessing peroxidase (PER) and superoxide dismutase (SOD) activities according to the method described previously (Ferreira et al., 2015). Untreated cells were used as control. Soluble protein was determined using the Bradford test using a standard curve of bovine serum albumin.

\section{Cell Diameter, Capsule Size, and Zeta Potential Measurements}

Yeasts cells cultured with $0.5 \times$ MIC (MIC eugenol $=128 \mathrm{mg} / \mathrm{L}$ for C. gattii ATCC 24065, C. neoformans ATCC 28957, and C. neoformans ATCC 62066; $32 \mathrm{mg} / \mathrm{L}-$ C. gattii ATCC 32068) of eugenol were visualized with an optical microscope $100 \times$ (Axioplan; Carl Zeiss, Germany) following suspension in India ink. Capsule size was measured as the difference between the total cell size and the cell body diameter and total cell size may be defined as the diameter of the complete cell including the capsule. The measurements were done with of at least 50 cells were measured using ImageJ $1.40 \mathrm{~g}$ software ${ }^{1}$ (National Institutes of Health, NIH, Bethesda, MD, United States) (Araujo

${ }^{1}$ http://rsb.info.nih.gov/ij/
Gde et al., 2012). Final measurements were presented as ratio of capsule size/cell diameter ratio. In addition, the surfaceto-volume ratio $(\mathrm{S} / \mathrm{V})$ was calculated using the formula $3 / r$, where $r$ is radius (Ferreira et al., 2015). Zeta potential (ZP) experiments were performed using Malvern Zetasizer Nano ZS equipment. The ZP was determined by Laser Doppler Microelectrophoresis technique, at scattering angle of $173^{\circ}$, using a disposable cell folded capillary (DPS1060). ZP values were calculated as the average of ten independent measurements, each obtained as the mean of 30 counts (Nosanchuk et al., 1999).

\section{Isothermal Titration Calorimetry (ITC)}

Isothermal titration calorimetry (ITC) experiments were carried out with one repetition using a VP-ITC microcalorimeter (Microcal LCC, Northampton, MA, United States) at $25^{\circ} \mathrm{C}$, after previous electrical and chemical calibration. All the solutions employed in the experiment were previously degasified under vacuum (140 mbar) during $8 \mathrm{~min}$. Each titration experiment consisted of 51 successive injections of $5 \mu \mathrm{L}$ of eugenol at $1024 \mathrm{mg} / \mathrm{L}$ in a chamber containing $1.5 \mathrm{~mL}$ of C. neoformans suspension at $1 \times 10^{6} \mathrm{CFU} / \mathrm{mL}$. The first $1 \mathrm{~mL}$ injection was discarded to eliminate diffusion effects of material from the syringe to the calorimetric chamber. The injection time was $2 \mathrm{~s}$ and the interval between the injections was $240 \mathrm{~s}$ (Abraham et al., 2005; Raudino et al., 2011).

\section{Statistical Analyses}

Results are shown as means \pm SEM and $P$-values $\leq 0.05$ were taken to indicate statistical significance. All statistical analyses were performed using GraphPad Prism version 5.00 for Windows (GraphPad Software, San Diego, CA, United States). Statistical significance among two groups was determined by Student's $t$-test (parametric data) or Mann-Whitney test (non-parametric data) and multiple comparisons were analyzed by one-way analysis of variance (ANOVA). Zeta Plus software was used for Zeta potential (Brookhaven Instruments Corp., Holtsville, NY, United States).

\section{RESULTS}

\section{Antifungal Drug Susceptibility Testing, Time-Kill Curves, and Interaction between Eugenol and Antifungal Drugs}

In the antifungal susceptibility testing, MIC range values for eugenol 64.0-256 (Figure 1A). To evaluate the kinetics of the action of the antifungal agents tested, the time-kill curve assay was performed. Eugenol provided fungicide curves, with complete reduction of growth after $36 \mathrm{~h}$ against C. gattii and $72 \mathrm{~h}$ against $C$. neoformans, both in MIC concentration (Figure 1B), and $2 \times$ MIC (data no shown). It was observed that there was no interaction between eugenol and the antifungal drugs fluconazole and amphotericin B against two C. gattii strains and two C. neoformans strains (Figure 1C). 
A

\begin{tabular}{|c|c|c|c|}
\hline Strains & $\begin{array}{c}\text { MIC } \\
\text { EUG }\left(\mathrm{mg} / \mathrm{L}^{*}\right.\end{array}$ & Strains & $\begin{array}{c}\text { MIC } \\
\text { EUG(mg/L } \\
\end{array}$ \\
\hline C. gattii & & $\begin{array}{c}\text { C. } \\
\text { neoformans }\end{array}$ & \\
\hline $\begin{array}{l}\text { ATCC } \\
24065\end{array}$ & 256 & ATCC 28957 & 256 \\
\hline $\begin{array}{l}\text { ATCC } \\
32068\end{array}$ & 64 & ATCC 24067 & 256 \\
\hline L28/02 (C) & 256 & ATCC 62066 & 256 \\
\hline 196L/03 (C) & 256 & LMM $820(\mathrm{C})$ & 128 \\
\hline 1913ER (C) & 256 & C-3-1 (E) & 128 \\
\hline $\begin{array}{c}547 / O T T / / 94 \\
-\mathrm{PI}-10(\mathrm{E})\end{array}$ & 256 & WP $(C)$ & 256 \\
\hline $\mathrm{L} 27 / 01(\mathrm{C})$ & 256 & $5396(C)$ & 64 \\
\hline LMM818 (C) & 256 & $96806(\mathrm{C})$ & 256 \\
\hline $\mathrm{L} 24 / 01(\mathrm{C})$ & 128 & 27JF (C) & 128 \\
\hline MIC 50 & 256 & MIC 50 & 256 \\
\hline MIC 90 & 256 & MIC 90 & 256 \\
\hline $\begin{array}{c}\text { Geometric } \\
\text { Mean }\end{array}$ & 200 & $\begin{array}{c}\text { Geometric } \\
\text { Mean }\end{array}$ & 187 \\
\hline
\end{tabular}

B

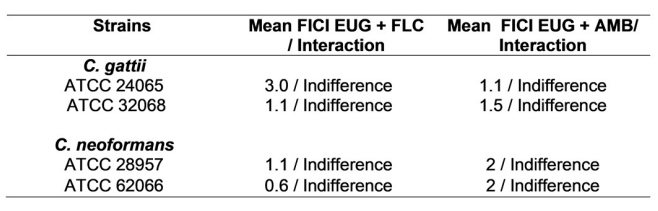

C

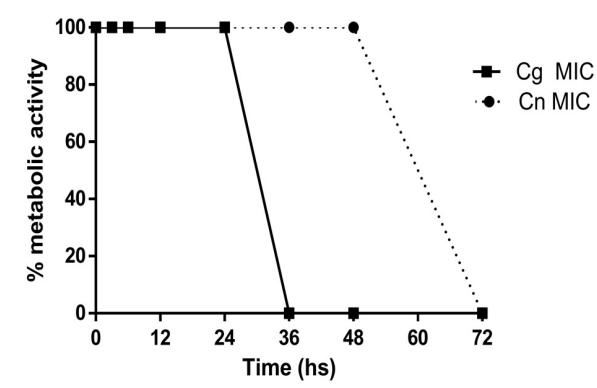

FIGURE 1 | Table contents of minimum inhibitory concentration of eugenol (EUG) against the Cryptococcus gattii (Cg) and C. neoformans (Cn) strains using CLSI method (A); values of interactions of antifungal drugs with eugenol $\mathrm{Cg}$ and $\mathrm{Cn}$ strains and (B); and time-kill curves of EUG against $\mathrm{C}$. gattii (filled squares) and C. neoformans (filled circles) (C). Results of time-kill curve are expressed as the percentage of metabolic activity compared with the control growth. Data represent the mean of three independent experiments in duplicate assays. MIC, Minimal Inhibitory Concentration; C, Clinical; E, Environmental; EUG, Eugenol; FLC,

Fluconazole, AMB, Amphotericin B; FICl, fractional inhibitory concentration index.

\section{Sorbitol Test and Ergosterol Quantification}

The results of the assays with sorbitol showed no alterations of MIC when the cryptococcal cells are exposed to the osmotic protector sorbitol (Figure 2A). It should be noted that after $1 \mathrm{~h}$ of treatment with eugenol treatment, in both C. gattii and $C$. neoformans, ergosterol levels were not reduced in comparison to control. The group that received fluconazole treatment (positive control) showed significantly reduced levels of ergosterol in the two cryptococcal species tested $(P<0.05)$ (Figure 2B).

\section{Mitochondrial Membrane Potential}

Next, we attempted to analyze the effects of eugenol in $\Delta \Psi \mathrm{m}$ using an assay based on uptake and retention of Rho 123 . The results from cells incubated for $1 \mathrm{~h}$ demonstrated no significant differences between eugenol-treated cells and cells with no treatment (Supplementary Figure S1). However, for $12 \mathrm{~h}$ of incubation, both concentrations of eugenol (MIC and $2 \times \mathrm{MIC}$ ) provoked mitochondrial depolarization as the Rho 123 fluorescence signal significantly decreased for all treated-strains when compared with control cells $(P<0.05)$ (Figure 3).

We observed relative fluorescence intensity (\%) reduced to $16.92 \pm 0.25$ (MIC) and to $10.63 \pm 0.76(2 \times$ MIC) for C. gattii ATCC 24065. When C. gattii ATCC 32068 was analyzed, a smaller reduction was observed, with relative fluorescence intensities of $44.79 \pm 0.77$ and $88.27 \pm 2.57$ for the MIC and $2 \times$ MIC, respectively. For C. neoformans ATCC 28957, we observed a relative fluorescence intensity (\%) reduced to $72.14 \pm 0.88$ (MIC) and to $23.71 \pm 0.01(2 \times \mathrm{MIC})$. And for C. neoformans ATCC 62066 , a bigger reduction was observed, with relative fluorescence intensities of $54.51 \pm 0.59$ and $11.12 \pm 0.15$ for the MIC and $2 \times$ MIC, respectively (Figure 3).

\section{Lysosomal Membrane Stability}

The functionality of yeast lysosomes after eugenol treatment was evaluated using $\mathrm{AO}$ staining followed by flow cytometry analysis and microscopy fluorescence. Untreated cells exhibited intact lysosomes marked by a strong fluorescence emission in the FL3 channel. The results from cells incubated for $1 \mathrm{~h}$ demonstrated no significant differences between eugenol-treated cells and cells with no treatment (Supplementary Figure S2). Eugenol significantly reduced the lysosomal integrity $(P<0.05)$ (Figure 4).

We observed relative fluorescence intensity (\%) reduced to $15.68 \pm 0.35$ (MIC) and to $9.74 \pm 0.01$ (2xMIC) for C. gattii ATCC 24065. When C. gattii ATCC 32068 was analyzed, a smaller reduction was observed, with relative fluorescence intensities of $78.07 \pm 0.55$ and $64.97 \pm 0.58$ for the MIC and $2 \times$ MIC, respectively. For C. neoformans ATCC 28957, we observed a relative fluorescence intensity (\%) reduced to $74.89 \pm 1.34$ (MIC) and to $59.39 \pm 1.20$ ( $2 \times \mathrm{MIC})$. And for C. neoformans ATCC 62066 , a bigger reduction was observed, with relative fluorescence intensities of $43.60 \pm 1.64$ and $21.61 \pm 0.45$ for the MIC and $2 \times$ MIC, respectively (Figure 4).

\section{Lipid Peroxidation and ROS Production}

Our results showed high levels of TBARS after $1 \mathrm{~h}$ treatment with eugenol (C. gattii - no treated: $7.52 \pm 0.40 \mathrm{nmol}$, 


\begin{tabular}{cc}
\hline A Strains & $\begin{array}{c}\text { Mean FICI Sorbitol + EUG I } \\
\text { Interaction }\end{array}$ \\
\hline C. gattii & $1.1 /$ Indifference \\
ATCC 24065 & $1.5 /$ Indifference \\
ATCC 32068 & \\
& \\
C. neoformans & \\
ATCC 28957 & $0.6 /$ Indifference \\
ATCC 62066 & $0.8 /$ Indifference \\
\hline
\end{tabular}

B

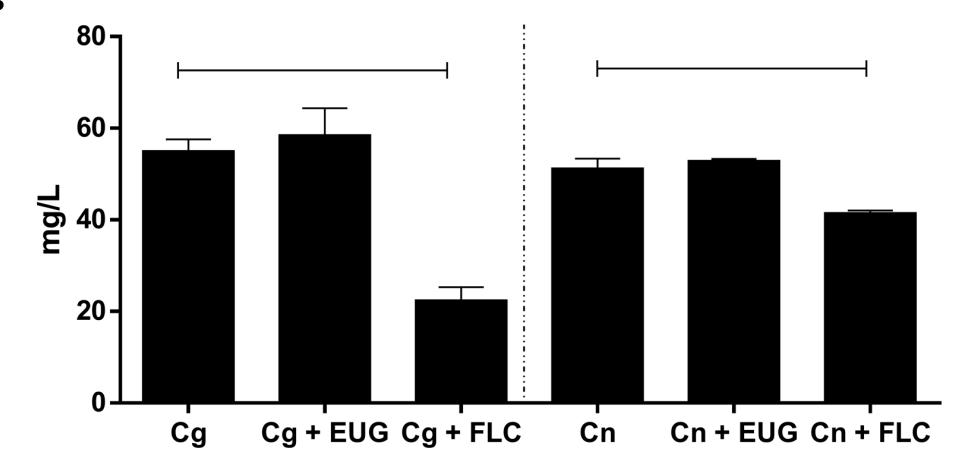

FIGURE 2 | Checkboard of EUG and sorbitol to C. gattii and C. neoformans (A); and levels of ergosterol content of Cg and Cn strains after 1 h of treatment with EUG and fluconazole (FLC; positive control). Results are expressed in mg/L. Statistically differences between the antifungal drugs and the control are represented by connect line $(P<0.05)$ (B). Data represent the mean \pm SEM of two independent experiments in triplicate assays. MIC, Minimal Inhibitory Concentration; EUG, Eugenol; FLC, Fluconazole, $\mathrm{FICl}$, fractional inhibitory concentration index.

treated: $15.24 \pm 0.15 \mathrm{nmol}$; C. neoformans - no treated: $9.68 \pm 0.13 \mathrm{nmol}$, treated: $18.33 \pm 0.86 \mathrm{nmol})$ with the growth control $(P<0.05)$ and hydrogen peroxide (positive control), indicating damage of the lipids compared (Figure 5A). It is well established that lipid peroxidation is mediated by free radicals. Thus, it was hypothesized that this effect may be related to ROS. Eugenol resulted in a significantly increasing ROS levels compared with the growth control after $1 \mathrm{~h}$ of treatment (C. gattii - no treated: $347.00 \pm 33.31 \mathrm{AU}$, treated: $404.06 \pm 26.24 \mathrm{AU} ; C$. neoformans - no treated: $449.60 \pm 59.99$ AU, treated: $560.00 \pm 27.98 \mathrm{AU})(P<0.05)$ (Figure 5B).

\section{Antioxidant PER and SOD Activities}

To determine whether treatment with eugenol influences the antioxidant enzymes, activities of SOD and PER were assessed. The results showed that is no difference in SOD (C. gattii no treated: $13568.00 \pm 899.80$ units $/ \mathrm{mg}$ of protein, treated: $14016.00 \pm 4581.00$ units/mg of protein; C. neoformans no treated: $7099.00 \pm 1097.00$ units $/ \mathrm{mg}$ of protein, treated: $9970.00 \pm 947.20$ units/mg of protein $)(P<0.05)$ (Figure $5 \mathrm{C})$ and PER (C. gattii - no treated: $1.32 \pm 0.23 \mathrm{nmol} / \mathrm{min} / \mathrm{mg}$ of protein, treated: $1.28 \pm 0.23 \mathrm{nmol} / \mathrm{min} / \mathrm{mg}$ of protein; C. neoformans no treated: $1.11 \pm 0.38 \mathrm{nmol} / \mathrm{min} / \mathrm{mg}$ of protein, treated: $1.17 \pm 0.27 \mathrm{nmol} / \mathrm{min} / \mathrm{mg}$ of protein $)(P<0.05)$ (Figure 5D) activities in cells exposed to eugenol when compared to the growth control.

\section{Morphological Alterations}

Morphometric analysis showed that eugenol reduces significantly capsule size/cell diameter ratios (C. gattii - no treated: $0.27 \pm 0.005$, treated: $0.18 \pm 0.005 ;$ C. neoformans - no treated: $0.21 \pm 0.007$, treated: $0.18 \pm 0.006)(P<0.05)$ (Figure 6A) and surface/volume $(\mathrm{s} / \mathrm{v})$ ratios $(C$. gattii - no treated: $0.57 \pm 0.01$, treated: $0.78 \pm 0.01 ;$ C. neoformans - no treated: $0.61 \pm 0.008$, treated: $0.78 \pm 0.009)(P<0.05)$ (Figure 6B) of $C$. gatii and C. neoformans. Examples of images that support the data are in the Figure 6C. Moreover, using a zeta potential analyzer it could be noted that eugenol treatment caused an increase of the cellular superficial charges in both C. gattii and C. neoformans (C. gattii no treated: $-9.17 \pm 01.32 \mathrm{z} / \mathrm{mV}$, treated: $0.21 \pm 0.19 \mathrm{z} / \mathrm{mV}$; C. neoformans - no treated: $-8.91 \pm 0.35$, treated: $0.20 \pm 0.17)$ $(P<0.05)$ (Figure 6D).

As a means of studying lysosomal membrane integrity in yeasts, we recorded imagens in a fluorescent microscopy from stained cells with AO using 495-555 nm filter. Treatment of eugenol promote a loss of the lysosomal $\mathrm{pH}$ gradient and subsequent leakage of AO into the cytosol (Petersen et al., 2010), that results in rise in green fluorescence when we compared with cells no treated with eugenol (Figure 6C).

\section{Thermodynamics of the Interaction of Eugenol with C. neoformans}

Aiming to analyze the molecular interactions between eugenol and cryptococcal cells, enthalpy changes of this 
A

\begin{tabular}{c|c|c|c}
\hline \multirow{2}{*}{ Strains } & \multicolumn{3}{|c}{ Mitochondrial membrane potential } \\
\cline { 2 - 4 } & Ne treated & MIC & $2 \times$ MIC \\
\cline { 2 - 4 } C. gattii & $100.0 \pm 1.71$ & $16.92 \pm 0.25^{*}$ & $10.63 \pm 0.76^{*}$ \\
ATCC 24065 & & & \\
\hline C. gattii & $100.0 \pm 0.11$ & $44.79 \pm 0.77^{*}$ & $88.87 \pm 2.57^{*}$ \\
ATCC 32068 & & & \\
\hline C. neoformans & $100.0 \pm 0.67$ & $72.14 \pm 0.88^{*}$ & $23.71 \pm 0.01^{*}$ \\
ATCC 28957 & & & $11.12 \pm 0.15^{*}$ \\
\hline C. neoformans & $96.50 \pm 5.60$ & $54.51 \pm 0.59^{*}$ & \\
ATCC 62066 & & & \\
\hline
\end{tabular}

B

ATCC24065

ATCC32068

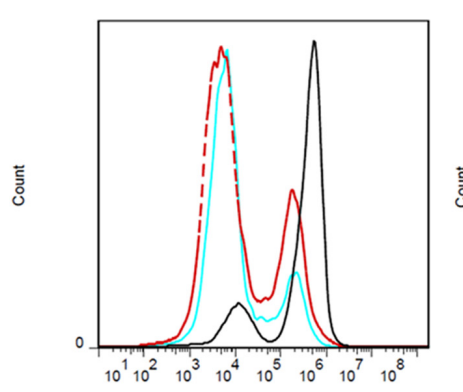

FL1-A:: FL1-A

FL1-A:: FL1-A
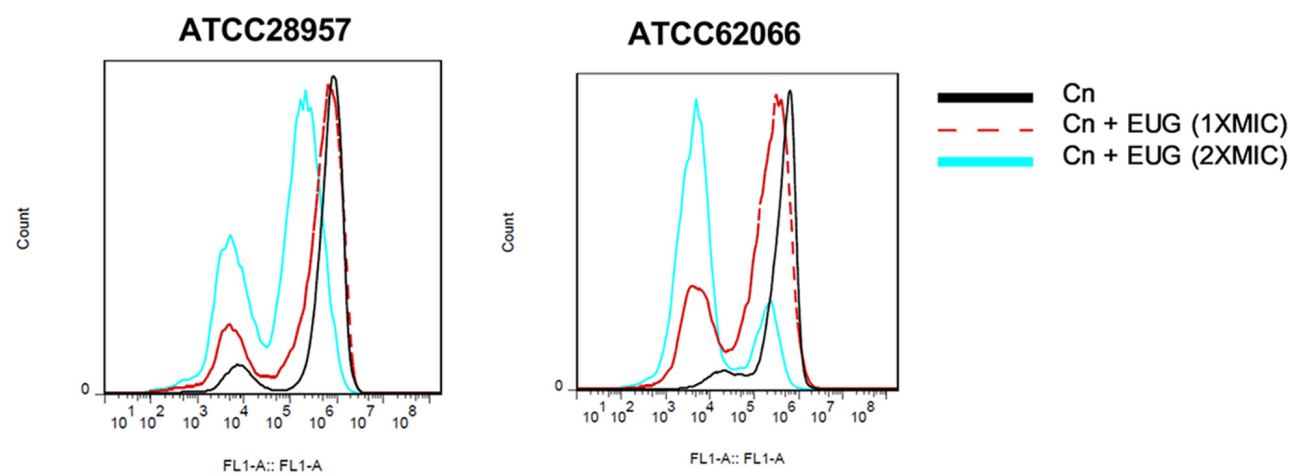

FIGURE 3 | Eugenol induces mitochondrial membrane depolarization of C. gattii (Cg) and C. neoformans (Cn) cells after 12 h of treatment. Data are shown by table (A) and by histograms (B). Statistically differences between the antifungal drugs and the control are represent by asterisks in table $(P<0.05)$. MIC, Minimal Inhibitory Concentration; EUG, Eugenol.

process were determined by ITC. Figure 7 shows that C. neoformans did not interact significantly with eugenol, since the enthalpy values of the group that received eugenol treatment were similarly of the blank experiment (eugenol in saline).

\section{DISCUSSION}

A small number of antimycotic drugs with different modes of action and target spectra are available to treat cryptococcosis, with polyenes and azoles being the most used 


\begin{tabular}{c|c|c|c}
\hline \multirow{2}{*}{ A } & \multicolumn{3}{|c}{ Lysosomal membrane stability } \\
\cline { 2 - 4 } & \multicolumn{2}{|c}{ Relative fluorescence intensity (\%) (Mean \pm Standard deviation) } \\
\cline { 2 - 4 } C. gattii & No treated & MIC & $2 \times M I C$ \\
\hline ATCC 24065 & $100.0 \pm 6.61^{*}$ & $15.68 \pm 0.35^{*}$ & $9.74 \pm 0.01^{*}$ \\
C. gattii & & & \\
ATCC 32068 & $100.0 \pm 1.91^{*}$ & $78.07 \pm 0.55^{*}$ & $64.97 \pm 0.58^{*}$ \\
\hline C. neoformans & & & \\
ATCC 28957 & $100.0 \pm 1.05^{*}$ & $74.89 \pm 1.34^{*}$ & $59.39 \pm 1.20^{*}$ \\
\hline C. neoformans & & & \\
ATCC 62066 & $100.0 \pm 0.19^{*}$ & $43.60 \pm 0.1 .64^{*}$ & $21.61 \pm 0.45^{*}$ \\
\hline
\end{tabular}

B

ATCC24065
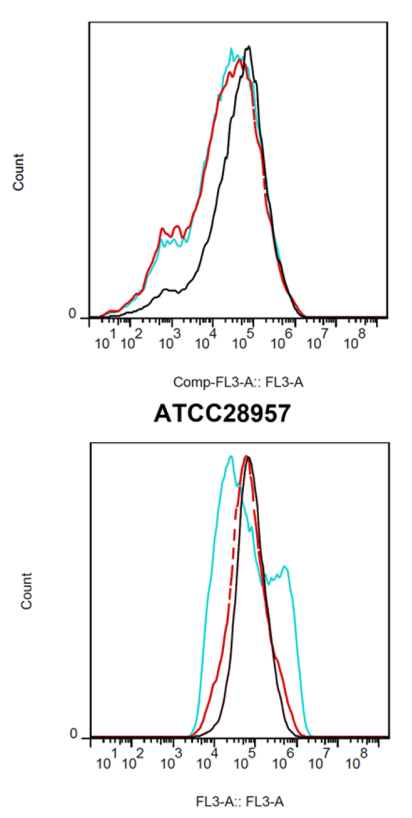

ATCC32068
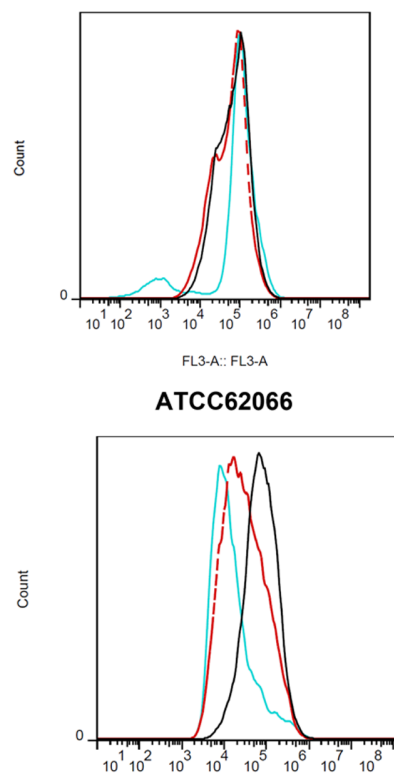

FL3-A.: FL3-A

FIGURE 4 | Eugenol reduces the lysosomal integrity of C. gattii (Cg) and C. neoformans (Cn) cells after $12 \mathrm{~h}$ of treatment. Data are shown by table (A) and by histograms (B). Statistically differences between the antifungal drugs and the control are represent by asterisks in table $(P<0.05)$. MIC, Minimal Inhibitory Concentration; EUG, Eugenol.

(Chayakulkeeree and Perfect, 2006). It is well established that the infection caused by $C$. gattii has a less favorable response to antifungal therapy and a relatively worse prognosis compared with the infection caused by $C$. neoformans (Kronstad et al., 2011). The rapid increase in the emergence of resistance against existing antifungal drugs created a need to discover new antifungal agents. Previous studies showed that eugenol has antifungal activity against $C$. neoformans, however, little is known about its activity against $C$. gattii and about its mechanism of action (Lemos et al., 2005; Carrasco et al., 2012). In this study, we provide evidence that eugenol has antimicrobial activity against C. gattii. Also, the present study gives a clear understanding and further validates a possible mode of action of eugenol against C. gattii and C. neoformans. 

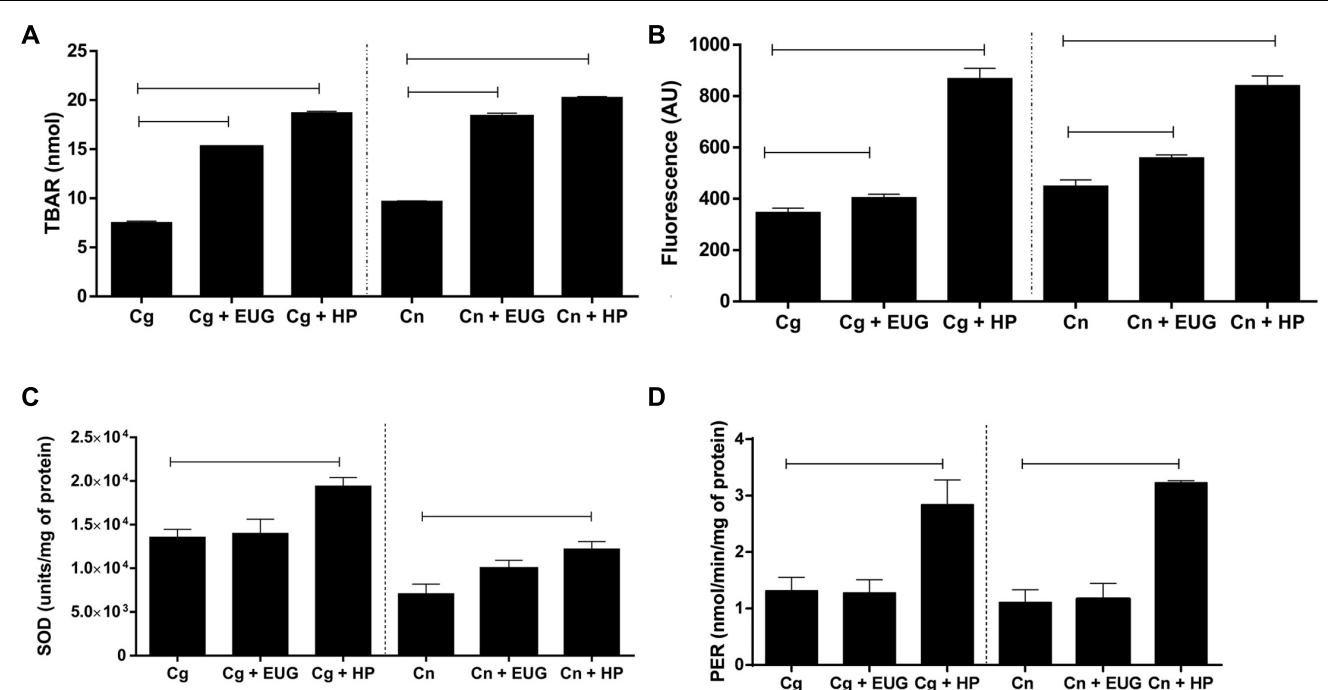

D

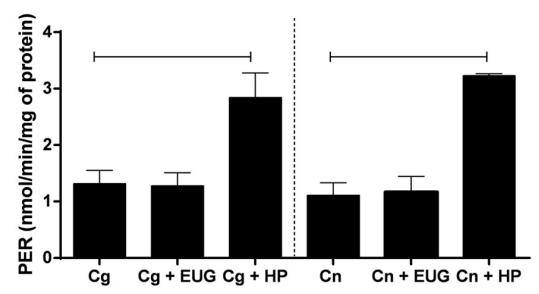

FIGURE 5 | Lipid peroxidation (A), amounts of reactive oxygen species (ROS) (B), superoxide dismutase (SOD) (C), and peroxidase (PER) (D) activities in C. gattii and C. neoformans strains after $1 \mathrm{~h}$ of treatment with eugenol (EUG) and hydrogen peroxide (HP; positive control). Lipid peroxidation results are expressed in nmol, ROS in arbitrary units (AU) of fluorescence, SOD in units $/ \mathrm{mg}$ of protein and PER in $\mathrm{nmol} / \mathrm{min} / \mathrm{mg}$ of protein. Statistically differences the treatments are represent by connect line $(P<0.05)$. Data represent the mean \pm SEM of two independent experiments in triplicate assays. MIC, Minimal Inhibitory Concentration; EUG, Eugenol; HP, Hydrogen Peroxide.

\section{A}

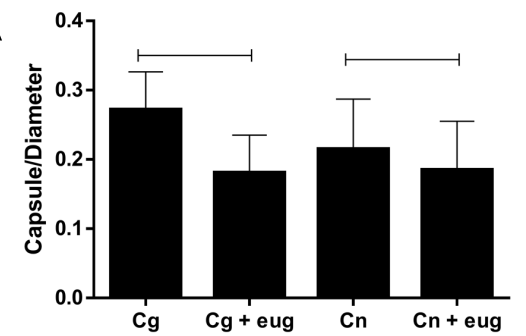

C

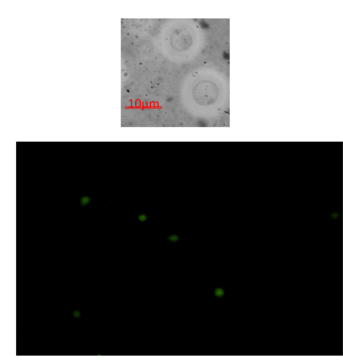

No treated

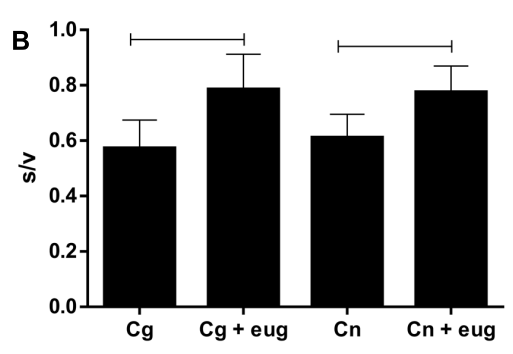

D

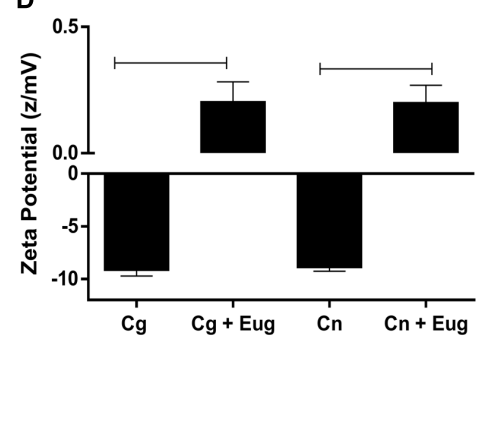

FIGURE 6 | Morphometric parameters and cellular charge are altered by the eugenol stress in C. gattii and C. neoformans strain. Capsule size/diameter (A); surface/volume (B); stained cells (India ink and acridine orange, AO) (C), and zeta potential (D) of cryptococcal cells treated with eugenol and with no stress. Morphometric data are expressed in ratio and zeta potential data are expressed in $\mathrm{z} / \mathrm{mV}$. Statistically differences the treatments are represent by connect line $(P<0.05)$. Data represent the mean \pm SEM of two independent experiments in triplicate assays. MIC, Minimal Inhibitory Concentration; EUG, Eugenol; FLC, Fluconazole; $\mathrm{FICl}$, fractional inhibitory concentration index.

The results of the in vitro susceptibility tests of the fungal isolates to eugenol, main constituent of essential oil of Ocimum gratissimum, presented MIC values range from 64 to $256 \mathrm{mg} / \mathrm{L}$ for both species. Similar results were found in previous studies for C. neoformans (Lemos et al., 2005; Carrasco et al., 2012). It is important to note that after combining fluconazole and amphotericin B, eugenol exert indifferent effect against C. gattii and $C$. neoformans in vitro. These results suggest that eugenol 


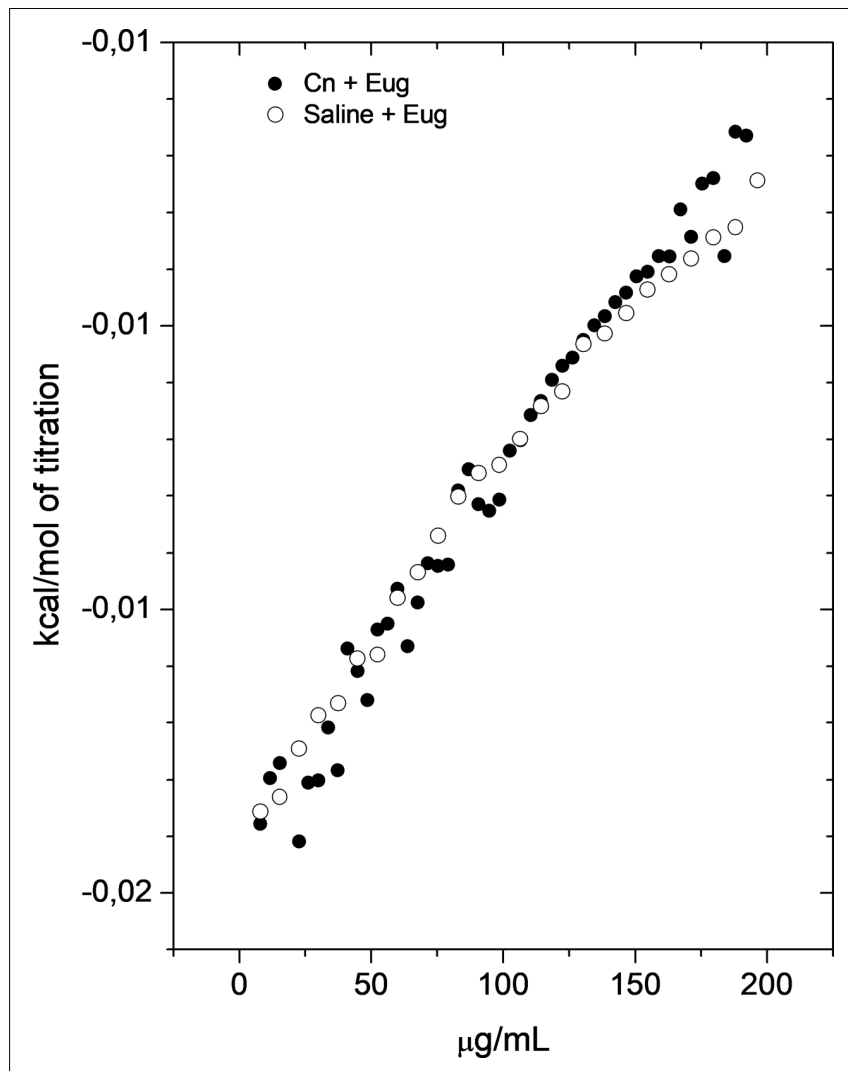

FIGURE 7 | Cryptococcus neoformans did not interact significantly with eugenol. Calorimetric titration curve for the dilution of concentrated EUG into saline solution (control) $(\bigcirc)$ and $C$. neoformans cells $(\mathbf{O})$. Each titration experiment consisted of 51 successive injections of $5 \mu \mathrm{L}$ of eugenol at $1024 \mathrm{mg} / \mathrm{L}$ in $1.5 \mathrm{~mL}$ of $C$. neoformans suspension at $1 \times 10^{6} \mathrm{CFU} / \mathrm{mL}$.

could be used together with fluconazole and amphotericin B for cryptococcosis treatment without prejudice to the action of these drugs, but more studies are necessary to confirm this hypothesis.

To provide clues if eugenol interferes on fungal cell-wall integrity, a checkerboard microdilution method was conducted with eugenol and sorbitol, an osmotic protectant used for stabilizing fungal protoplasts (Lemos et al., 2005; Carrasco et al., 2012). Results showed that MIC of eugenol did not vary in the presence of sorbitol, but more tests are necessary to prove this hypothesis.

Our results showed that eugenol does not disturb the amount of ergosterol in cryptococcal cells. Khan et al. (2013) found contradictory results using similar methodology for C. albicans when they studied the influence of eugenol on ergosterol and on cell wall. Otherwise, Carrasco et al. (2012) showed that the antifungal activity of eugenol derivative against $C$. albicans was not reversed in the presence of an osmotic support such as sorbitol, and does not seem to bind to ergosterol. We think that the data found for cryptococcal cells could be attributed to its encapsulated form. The capsular polysaccharide confers several physicochemical properties to the cell surface, including a negative surface charge and a hydrophilic surface (Araujo Gde et al., 2012), that could disturb eugenol mechanism of action.
High levels of TBARSs were observed after $1 \mathrm{~h}$ treatment with eugenol. Our results also show that eugenol caused an increase in intracellular amount of ROS. Based on these data, it was hypothesized that eugenol induces ROS production. Under dysfunctional mitochondria, electrons can escape from the electron transport chain to induce formation of superoxide anions by one-electron reduction of oxygen. In this, study it was shown that the presence of eugenol can contribute substantially to the generation of ROS, possibly triggered by disturbance in the mitochondrial membrane and a reduction of a lysosomal integrity. This event seems to be connected to the potential of eugenol to interfere with electronic mitochondrial membrane stabilization. Furthermore, the phenomenon of depolarization of the mitochondrial membrane can be evidenced by increased generation ROS, as seen by vanillin derivatives against C. neoformans (Kim et al., 2014). In addition, leading to lipid peroxidation, which corresponds to the oxidative degradation of lipids, in which a free radical chain 'steals' electrons from the lipids (mainly polyunsaturated fatty acids) in cell membranes, resulting in cell damage. Similar results were found for eugenol against C. albicans (Khan et al., 2013).

To better understand how the cryptococcal cells adapt to eugenol stress, we performed some experiments exposing the yeasts in sub inhibitory concentration of eugenol $(0.5 \times \mathrm{MIC})$. The assays demonstrated no difference on SOD and PER activities. The antioxidant system cell was not sufficient to neutralize the ROS induced by eugenol. It could explain the fungicidal action seen in time-kill curve.

Eugenol stress altered the cell morphology and induced a reduction in capsule size/cell diameter ratio and an increase in the surface/volume ratio. Similar results have been reported following the exposure of C. neoformans to fluconazole, voriconazole, amphotericin B, and terbinafine (Mondon et al., 1999; Nosanchuk et al., 1999; Guerra et al., 2012; Santos et al., 2014). Our group previously demonstrated that itraconazole promotes oxidative burst, and the cells adapt to this process diminishing the capsule size and cell diameter (Ferreira et al., 2013, 2015). This phenomenon could be explained as an attempt of the cells to adapt to different xenobiotics, since the capsule growth is associated to a slower yeast growth. Indeed, cells with high surface/volume ratio cells adapt more rapidly to abrupt changes in environmental conditions (Maxson et al., 2007; Ferreira et al., 2015).

Cryptococcal cells are negatively charged because of capsular polysaccharide and melanin (Kozel, 1983). As expected, the cells growth in the presence of eugenol decreased the magnitude of the negative charge, because they have smaller capsule than yeasts exposed to no stress. Based on this observation, we hypothesized that cells treated with eugenol would be more phagocytized by macrophages due to reduced electrostatic repulsion between yeast cells and phagocytes, but more studies are necessary to confirm this hypothesis.

To better understand the chemical nature of interaction between eugenol and superficial yeast molecules, we performed ITC. The analysis of this molecular interaction showed interaction with slow significant force. Hydrogen bonds, ionic interactions, covalent interactions are interactions that have a 
power of about 1.0 to $10 \mathrm{kcal} / \mathrm{mol}$. The non-polar interactions like and hydrophobic and induced dipole-dipole (Van der Walls) have energy lower than $1 \mathrm{kcal} / \mathrm{mol}$ and generate low enthalpy connection (Berg et al., 2002). Based on these informations, we supposed that eugenol interacts with cryptococcal cells through non-polar interactions.

\section{CONCLUSION}

The present results indicate that eugenol has antifugal effects against $C$. gattii and $C$. neoformans acting on the oxidative burst. It is known that eugenol is able to pass the blood-brain barrier, enter the brain and act in situ (Bahramsoltani et al., 2015). In this way, eugenol could be a possible molecule to the treatment of cryptococcosis, and could have its activity improved through organic modeling. Indeed, eugenol could be used as an auxiliary treatment to cutaneous cryptococcosis or another cutaneous mycosis (Chami et al., 2004; Lee et al., 2007).

\section{AUTHOR CONTRIBUTIONS}

JA, ÁS, BM, LVNFS: Execution, analysis, and interpretation of data for the tests about morphologic cell surface, ergosterol content, cellular wall integrity, lipid peroxidation, oxidative burst from the interaction of eugenol with cryptococcal cells. JS, LCNS, JR, WN, EF: Execution, analysis, and interpretation of data for the tests about lysosomal and mitochondrial integrity from the interaction of eugenol with cryptococcal cells. GF, DS, AM, VdS, AP, TR, LG: Conception or design of all the work, preparation of the article, and translation into English. ÂD: Execution, analysis, and interpretation of data for the tests about

\section{REFERENCES}

Abraham, T., Lewis, R. N., Hodges, R. S., and McElhaney, R. N. (2005). Isothermal titration calorimetry studies of the binding of a rationally designed analogue of the antimicrobial peptide gramicidin s to phospholipid bilayer membranes. Biochemistry 44, 2103-2112. doi: 10.1021/bi048077d

Araujo Gde, S., Fonseca, F. L., Pontes, B., Torres, A., Cordero, R. J., ZancopéOliveira, R. M., et al. (2012). Capsules from pathogenic and non-pathogenic Cryptococcus spp. manifest significant differences in structure and ability to protect against phagocytic cells. PLOS ONE 7:e29561. doi: 10.1371/journal. pone.0029561

Bahramsoltani, R., Farzaei, M. H., Farahani, M. S., and Rahimi, R. (2015). Phytochemical constituents as future antidepressants: a comprehensive review. Rev. Neurosci. 26, 699-719. doi: 10.1515/revneuro-2015-0009

Baptista, R., Madureira, A. M., Jorge, R., Adão, R., Duarte, A., Duarte, N., et al. (2015). Antioxidant and antimycotic activities of two native Lavandula species from Portugal. Evid. Based Complement. Alternat. Med. 2015:570521. doi: 10.1155/2015/570521

Berg, J. M., Tymoczko, J. L., and Stryer, L. (2002). Biochemistry: Section 1.3, Chemical Bonds in Biochemistry. New York, NY: W H Freeman.

Breivik, O. N., and Owades, J. L. (1957). Spectrophotometric semimicrodetermination of ergosterol in yeast. J. Agric. Food Chem. 5, 360-363. doi: 10.1021/jf60075a005

Capoor, M. R., Khanna, G., Malhotra, R., Verma, S., Nair, D., Deb, M., et al. (2008). Disseminated cryptococcosis with necrotizing fasciitis in an apparently immunocompetent host: a case report. Med. Mycol. 46, 269-273. doi: 10.1080/ 13693780701675797 the thermodynamics changes from the interaction of eugenol with cryptococcal cells.

\section{FUNDING}

This research was financially supported by Universidade Federal de Minas Gerais (UFMG), Universidade Federal de Juiz de Fora (UFJF), and Universidade Vale do Rio Doce (UNIVALE).

\section{ACKNOWLEDGMENT}

The authors are indebted to Prof. Gulnara P. B. Cabrera and Prof. Carlos M. A. Sobrinho from Universidade Vale do Rio Doce (UNIVALE).

\section{SUPPLEMENTARY MATERIAL}

The Supplementary Material for this article can be found online at: https://www.frontiersin.org/articles/10.3389/fmicb. 2017.02419/full\#supplementary-material

FIGURE S1 | Mitochondrial membrane depolarization of C. gattii (Cg) and C. neoformans (Cn) cells. Cg ATCC 24065 strain (A,B); Cg ATCC 32068 strain (C,D); Cn ATCC 28957 strain (E,F); Cn ATCC 62066 (G,H) strain after $1 \mathrm{~h}$ of treatment with eugenol. Data are shown by column graphs (mean $\pm \mathrm{SE}$ ) and by histograms. MIC, Minimal Inhibitory Concentration; EUG, Eugenol.

FIGURE S2 | Lysosomal integrity of C. gattii (Cg) and C. neoformans (Cn) cells. Cg ATCC 24065 strain (A,B); Cg ATCC 32068 strain (C,D); Cn ATCC 28957 strain (E,F); Cn ATCC 62066 (G,H) strain after 1 h of treatment with eugenol. Data are shown by column graphs (mean \pm SE) and by histograms. MIC, Minimal Inhibitory Concentration; EUG, Eugenol.

Carrasco, H., Raimondi, M., Svetaz, L., Di Liberto, M., Rodriguez, M. V., Espinoza, L., et al. (2012). Antifungal activity of eugenol analogues. Influence of different substituents and studies on mechanism of action. Molecules 17, 1002-1024. doi: 10.3390/molecules 17011002

Chami, F., Chami, N., Bennis, S., Trouillas, J., and Remmal, A. (2004). Evaluation of carvacrol and eugenol as prophylaxis and treatment of vaginal candidiasis in an immunosuppressed rat model. J. Antimicrob. Chemother. 54, 909-914. doi: $10.1093 / \mathrm{jac} / \mathrm{dkh} 436$

Chayakulkeeree, M., and Perfect, J. R. (2006). Cryptococcosis. Infect. Dis. Clin. North Am. 20, 507-544, v-vi. doi: 10.1016/j.idc.2006.07.001

Darvishi, E., Omidi, M., Bushehri, A. A., Golshani, A., and Smith, M. L. (2013). The antifungal eugenol perturbs dual aromatic and branched-chain amino acid permeases in the cytoplasmic membrane of yeast. PLOS ONE 8:e76028. doi: 10.1371/journal.pone.0076028

Ferreira, G. F., Baltazar Lde, M., Santos, J. R., Monteiro, A. S., Fraga, L. A., Resende-Stoianoff, M. A., et al. (2013). The role of oxidative and nitrosative bursts caused by azoles and amphotericin B against the fungal pathogen Cryptococcus gattii. J. Antimicrob. Chemother. 68, 1801-1811. doi: 10.1093/jac/ dkt114

Ferreira, G. F., Santos, J. R., Costa, M. C., Holanda, R. A., Denadai, A. M., Freitas, G. J., et al. (2015). Heteroresistance to itraconazole alters the morphology and increases the virulence of Cryptococcus gattii. Antimicrob. Agents Chemother. 59, 4600-4609. doi: 10.1128/aac.00466-15

Gast, C. E., Basso, L. R., Bruzual, I., and Wong, B. (2013). Azole resistance in Cryptococcus gattii from the Pacific Northwest: investigation of the role of ERG11. Antimicrob. Agents Chemother. 57, 5478-5485. doi: 10.1128/AAC. 02287-12 
Gazim, Z. C., Rodrigues, F., Amorin, A. C., de Rezende, C. M., Soković, M., Tešević, V., et al. (2014). New natural diterpene-type abietane from Tetradenia riparia essential oil with cytotoxic and antioxidant activities. Molecules 19, 514-524. doi: 10.3390/molecules19010514

Gill, A. O., and Holley, R. A. (2004). Mechanisms of bactericidal action of cinnamaldehyde against Listeria monocytogenes and of eugenol against L. monocytogenes and Lactobacillus sakei. Appl. Environ. Microbiol. 70, 5750-5755. doi: 10.1128/AEM.70.10.5750-5755.2004

Guerra, C. R., Ishida, K., Nucci, M., and Rozental, S. (2012). Terbinafine inhibits Cryptococcus neoformans growth and modulates fungal morphology. Mem. Inst. Oswaldo Cruz 107, 582-590. doi: 10.1590/S0074-02762012000500003

Hagen, F., Khayhan, K., Theelen, B., Kolecka, A., Polacheck, I., Sionov, E., et al. (2015). Recognition of seven species in the Cryptococcus gattii/Cryptococcus neoformans species complex. Fungal Genet. Biol. 78, 16-48. doi: 10.1016/j.fgb. 2015.02.009

Ikeda, T., Kaminaka, C., Yamamoto, Y., and Furukawa, F. (2014). Disseminated cryptococcosis-induced skin ulcers in a patient with autoimmune hepatitis. Case Rep. Dermatol. 6, 98-102. doi: 10.1159/000360978

Institute Clinical and Laboratory Standards (2008). Reference Method for Broth Dilution Antifungal Susceptibility Testing of Yeasts: Approved Standard M27-A3. Wayne, PA: CLSI.

Khan, A., Ahmad, A., Akhtar, F., Yousuf, S., Xess, I., Khan, L. A., et al. (2011). Induction of oxidative stress as a possible mechanism of the antifungal action of three phenylpropanoids. FEMS Yeast Res. 11, 114-122. doi: 10.1111/j.15671364.2010.00697.x

Khan, M. S., Ahmad, I., and Cameotra, S. S. (2013). Phenyl aldehyde and propanoids exert multiple sites of action towards cell membrane and cell wall targeting ergosterol in Candida albicans. AMB Express 3:54. doi: 10.1186/21910855-3-54

Kim, J. H., Lee, H. O., Cho, Y. J., Kim, J., Chun, J., Choi, J., et al. (2014). A vanillin derivative causes mitochondrial dysfunction and triggers oxidative stress in Cryptococcus neoformans. PLOS ONE 9:e89122. doi: 10.1371/journal. pone.0089122

Kozel, T. R. (1983). Dissociation of a hydrophobic surface from phagocytosis of encapsulated and non-encapsulated Cryptococcus neoformans. Infect. Immun. 39, 1214-1219.

Kronstad, J. W., Attarian, R., Cadieux, B., Choi, J., D'Souza, C. A., Griffiths, E. J., et al. (2011). Expanding fungal pathogenesis: Cryptococcus breaks out of the opportunistic box. Nat. Rev. Microbiol. 9, 193-203. doi: 10.1038/nrmicro2522

Lee, S. J., Han, J. I., Lee, G. S., Park, M. J., Choi, I. G., Na, K. J., et al. (2007). Antifungal effect of eugenol and nerolidol against Microsporum gypseum in a guinea pig model. Biol. Pharm. Bull. 30, 184-188. doi: 10.1248/bpb.30.184

Lemos, J. A., Passos, X. S., Fernandes Ode, F., Paula, J. R., Ferri, P. H., Souza, L. K., et al. (2005). Antifungal activity from Ocimum gratissimum L. towards Cryptococcus neoformans. Mem. Inst. Oswaldo Cruz 100, 55-58. doi: 10.1590/ S0074-02762005000100011

Louie, G. V., Baiga, T. J., Bowman, M. E., Koeduka, T., Taylor, J. H., Spassova, S. M., et al. (2007). Structure and reaction mechanism of basil eugenol synthase. PLOS ONE 2:e993. doi: 10.1371/journal.pone.0000993

Magalhães, T. F., da Silva, C. M., de Fátima, A., da Silva, D. L., Modolo, L. V., Martins, C. V., et al. (2013). Hydroxyaldimines as potent in vitro anticryptococcal agents. Lett. Appl. Microbiol. 57, 137-143. doi: 10.1111/lam. 12086

Maxson, M. E., Cook, E., Casadevall, A., and Zaragoza, O. (2007). The volume and hydration of the Cryptococcus neoformans polysaccharide capsule. Fungal Genet. Biol. 44, 180-186. doi: 10.1016/j.fgb.2006.07.010
Mondon, P., Petter, R., Amalfitano, G., Luzzati, R., Concia, E., Polacheck, I., et al. (1999). Heteroresistance to fluconazole and voriconazole in Cryptococcus neoformans. Antimicrob. Agents Chemother. 43, 1856-1861.

Nosanchuk, J. D., Cleare, W., Franzot, S. P., and Casadevall, A. (1999). Amphotericin B and fluconazole affect cellular charge, macrophage phagocytosis, and cellular morphology of Cryptococcus neoformans at subinhibitory concentrations. Antimicrob. Agents Chemother. 43, $233-239$.

Odds, F. C. (2003). Synergy, antagonism, and what the chequerboard puts between them. J. Antimicrob. Chemother. 52:1. doi: 10.1093/jac/dkg301

Olsson, M., Rundquist, I., and Brunk, U. (1987). Flow cytofluorometry of lysosomal acridine orange uptake by living cultured cells. Effect of trypsinization and starvation. Acta Pathol. Microbiol. Immunol. Scand. A 95, 159-165.

Perugini Biasi-Garbin, R., Saori Otaguiri, E., Morey, A. T., Fernandes da Silva, M., Belotto Morguette, A. E., Armando Contreras Lancheros, C., et al. (2015). Effect of eugenol against Streptococcus agalactiae and synergistic interaction with biologically produced silver nanoparticles. Evid. Based Complement. Alternat. Med. 2015:861497. doi: 10.1155/2015/861497

Petersen, N. H., Kirkegaard, T., Olsen, O. D., and Jäättelä, M. (2010). Connecting Hsp70, sphingolipid metabolism and lysosomal stability. Cell Cycle 9, 2305-2309. doi: 10.4161/cc.9.12.12052

Raudino, A., Sarpietro, M. G., and Pannuzzo, M. (2011). The thermodynamics of simple biomembrane mimetic systems. J. Pharm. Bioallied Sci. 3, 15-38. doi: 10.4103/0975-7406.76462

Ronot, X., Benel, L., Adolphe, M., and Mounolou, J. C. (1986). Mitochondrial analysis in living cells: the use of rhodamine 123 and flow cytometry. Biol. Cell 57, 1-7. doi: 10.1111/j.1768-322X.1986.tb00458.x

Santos, J. R., Gouveia, L. F., Taylor, E. L., Resende-Stoianoff, M. A., Pianetti, G. A., César, I. C., et al. (2012). Dynamic interaction between fluconazole and amphotericin B against Cryptococcus gattii. Antimicrob. Agents Chemother. 56, 2553-2558. doi: 10.1128/AAC.06098-11

Santos, J. R., Holanda, R. A., Frases, S., Bravim, M., Araujo Gde, S., Santos, P. C., et al. (2014). Fluconazole alters the polysaccharide capsule of Cryptococcus gattii and leads to distinct behaviors in murine Cryptococcosis. PLOS ONE 9:e112669. doi: 10.1371/journal.pone.0112669

Scorzoni, L., de Paula, E., Silva, A. C., Marcos, C. M., Assato, P. A., de Melo, W. C., et al. (2017). Antifungal therapy: new advances in the understanding and treatment of mycosis. Front. Microbiol. 8:36. doi: 10.3389/fmicb.2017. 00036

Tadić, V., Bojović, D., Arsić, I., Dorđević, S., Aksentijevic, K., Stamenić, M., et al. (2012). Chemical and antimicrobial evaluation of supercritical and conventional Sideritis scardica Griseb., Lamiaceae extracts. Molecules 17, 2683-2703. doi: 10.3390/molecules 17032683

Conflict of Interest Statement: The authors declare that the research was conducted in the absence of any commercial or financial relationships that could be construed as a potential conflict of interest.

Copyright (c) 2017 Alves, Ferreira, Santos, Silva, Rodrigues, Neto, Farah, Santos, Mendes, Sousa, Monteiro, dos Santos, Santos, Perez, Romero, Denadai and Guzzo. This is an open-access article distributed under the terms of the Creative Commons Attribution License (CC BY). The use, distribution or reproduction in other forums is permitted, provided the original author(s) or licensor are credited and that the original publication in this journal is cited, in accordance with accepted academic practice. No use, distribution or reproduction is permitted which does not comply with these terms. 